\title{
Current status of robotic bariatric surgery: a systematic review
}

\author{
Roberto Cirocchi ${ }^{1}$, Carlo Boselli ${ }^{2}$, Alberto Santoro ${ }^{3}$, Salvatore Guarino ${ }^{3}$, Piero Covarelli ${ }^{2}$, Claudio Renzi ${ }^{2 *}$, \\ Chiara Listorti ${ }^{2}$, Stefano Trastulli ${ }^{1}$, Jacopo Desiderio ${ }^{1}$, Andrea Coratti ${ }^{4}$, Giuseppe Noya ${ }^{2}$, Adriano Redler ${ }^{3}$ \\ and Amilcare Parisi ${ }^{1}$
}

\begin{abstract}
Background: Bariatric surgery is an effective treatment to obtain weight loss in severely obese patients. The feasibility and safety of bariatric robotic surgery is the topic of this review.

Methods: A search was performed on PubMed, Cochrane Central Register of Controlled Trials, BioMed Central, and Web of Science.

Results: Twenty-two studies were included. Anastomotic leak rate was $8.51 \%$ in biliopancreatic diversion. 30-day reoperation rate was $1.14 \%$ in Roux-en-Y gastric bypass and $1.16 \%$ in sleeve gastrectomy. Major complication rate in Roux-en-Y gastric bypass resulted higher than in sleeve gastrectomy ( 4,26\% vs. 1,2\%). The mean hospital stay was longer in Roux-en-Y gastric bypass (range 2.6-7.4 days).

Conclusions: The major limitation of our analysis is due to the small number and the low quality of the studies, the small sample size, heterogeneity of the enrolled patients and the lack of data from metabolic and bariatric outcomes. Despite the use of the robot, the majority of these cases are completed with stapled anastomosis. The assumption that robotic surgery is superior in complex cases is not supported by the available present evidence. The major strength of the robotic surgery is strongly facilitating some of the surgical steps (gastro-jejunostomy and jejunojejunostomy anastomosis in the robotic Roux-en-Y gastric bypass or the vertical gastric resection in the robotic sleeve gastrectomy).
\end{abstract}

Keywords: Morbid obesity, Bariatric surgery, Robotic, Roux-en-Y gastric bypass, Robot assisted, Gastric bypass, Sleeve gastrectomy, Gastric banding, Duodenal switch, Surgical outcomes, Complications, Anastomotic leak

\section{Background}

The increased prevalence of obesity in the general population over the past 30 years encouraged researches focused on the development of new treatment options to achieve long-lasting weight loss. Besides noninvasive conservative treatments (e.g. lifestyle modifications, medical treatment, and behavioral therapy), bariatric surgery is now playing an important role in the treatment for obesity. In 1991 the National Institutes of Health Conference Statement on Gastrointestinal Surgery for Severe Obesity developed a consensus stating that bariatric surgery was the most effective treatment for obesity since it is associated with

\footnotetext{
* Correspondence: renzicla@virgilio.it

${ }^{2}$ Department of General and Oncologic Surgery, University of Perugia, Perugia, Italy

Full list of author information is available at the end of the article
}

good long-term results in terms of weight loss, glycemic control and decreased mortality [1]. It is widely recognized the growing incidence of obesity and diabetes mellitus as one of the major public burden in the western countries [2]. Current pharmacotherapy provides improvements in only less than $50 \%$ of patients with moderate to severe type 2 diabetes mellitus (T2DM). In the United States Roux-en-Y gastric bypass (RYGB) represents the most common bariatric surgical procedure [3]. Adam et al., in their Clinical Controlled Trial, enrolled 1.156 severely obese patients (BMI $\geq 35 \mathrm{~kg} / \mathrm{m} 2)$; they demonstrated that the RYGB surgery induced a significant weight loss, the best health-related quality of life and reduction of major obesity-related complications [4]. The only limit of bariatric surgery is represented by elevate peri-operative morbidity and mortality; in the attempt to reduce and limit this
C Biomed Central

(C) 2013 Cirocchi et al.; licensee BioMed Central Ltd. This is an open access article distributed under the terms of the Creative Commons Attribution License (http://creativecommons.org/licenses/by/2.0), which permits unrestricted use, distribution, and reproduction in any medium, provided the original work is properly cited. 


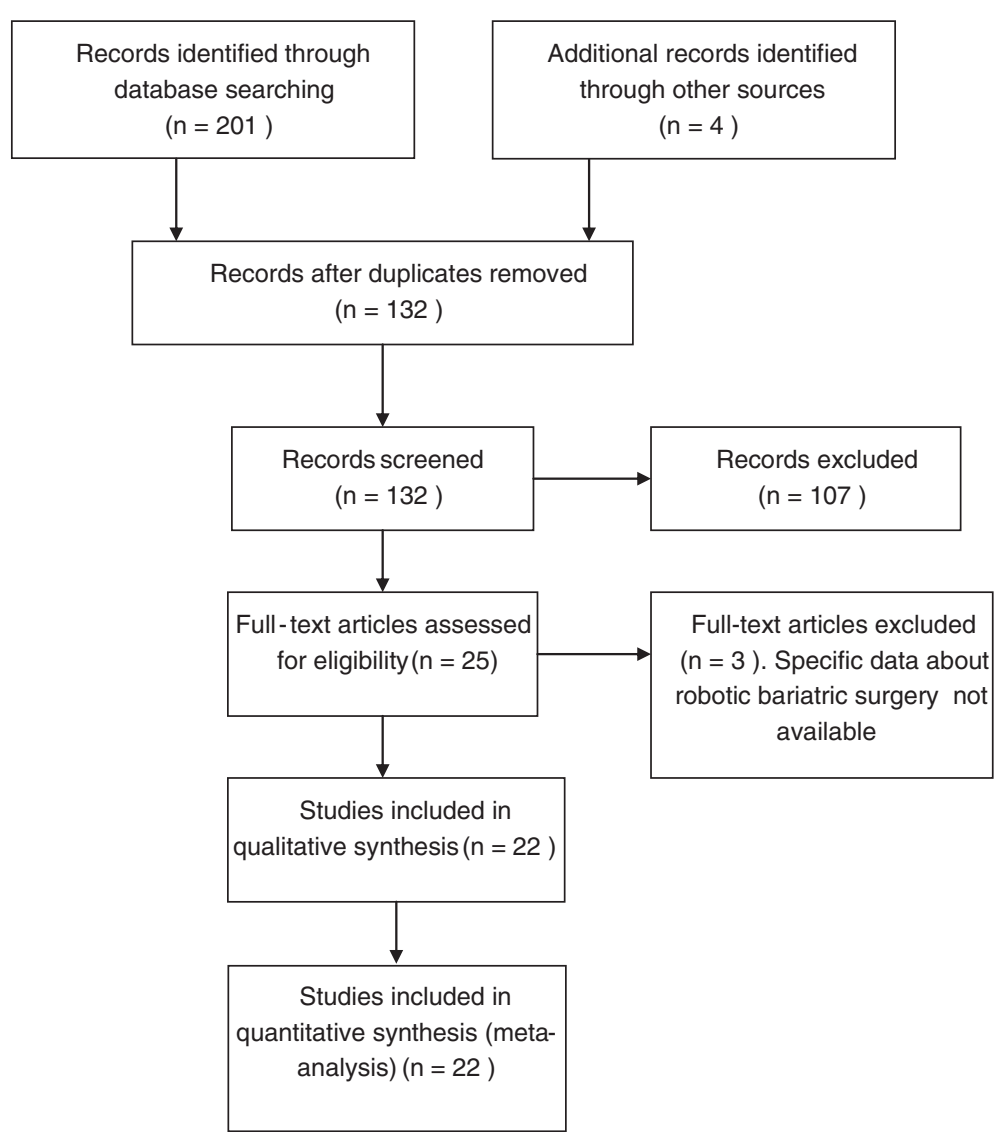

Figure 1 PRISMA flow chart of literature search.

important issue, Minimally Invasive Surgical techniques, initially laparoscopic and then robotic, are becoming more and more frequent [5]. The feasibility and safety are still debated. In 2011 a meta-analysis by Markar highlighted a decreased anastomotic stricture rate in patients undergoing Robotic RYGB (RRYGB) compared to the traditional laparoscopic approach $(\mathrm{P}=0.04)$ [6]. Recently Hagen et al. demonstrated that RRYGB reduced cost of surgery by avoiding the anastomosis-related complications [7]; this was in contrast with the results presented by Scozzari et al. [8]. In their study they concluded that RRYGBP does not associate with significant shorter hospital stay and fewer complications compared to the traditional laparoscopic procedure $[7,8]$. Recently, a number of studies were published on this subject, for this reason, despite three systematic review were already published [9-11], a new systematic one was needed in order to evaluate the present state of the literature on robotic bariatric surgery.

\section{Methods}

A systematic literature search was performed on PubMed, Cochrane Central Register of Controlled Trials, BioMed Central and on Web of Science from January 2003 to November 2012. The Preferred Reporting Items for
Systematic Reviews and Meta-analyses (PRISMA) was followed 005B [12]. Additional file 1. The following search strategies were used in PubMed:

- Robot-assisted [All Fields] AND ("bariatric surgery"[MeSH Terms] OR ("bariatric"[All Fields] AND "surgery"[All Fields]) OR "bariatric surgery"[All Fields])

- Robot-assisted [All Fields] AND ("gastric bypass"[MeSH Terms] OR ("gastric"[All Fields] AND "bypass"[All Fields]) OR "gastric bypass" [All Fields] OR "roux en y gastric bypass"[All Fields]) Robot-Assisted[All Fields] AND Sleeve[All Fields] AND ("gastrectomy"[MeSH Terms] OR "gastrectomy"[All Fields])

- ("robotics"[MeSH Terms] OR "robotics"[All Fields] OR "robotic"[All Fields]) AND ("bariatric surgery"[MeSH Terms] OR ("bariatric"[All Fields] AND "surgery" [All Fields]) OR "bariatric surgery"[All Fields])

- ("robotics"[MeSH Terms] OR "robotics" [All Fields] OR "robotic"[All Fields]) AND ("Band"[Journal] OR "band"[All Fields])

All titles and abstracts were assessed to select those focusing on robotic bariatric surgery. Subsequently, 
Table 1 Characteristics of the included studies: setting and technique

\begin{tabular}{|c|c|c|c|c|c|c|c|}
\hline Study* & $\begin{array}{l}\text { Years of } \\
\text { the study }\end{array}$ & City Nation & Type of trial & N. of patients & Author's definition of Robotic treatment & Type of treatment & Type of technique \\
\hline \multirow[t]{3}{*}{ Abdalla [15] 2012} & \multirow[t]{3}{*}{$2008-2011$} & \multirow[t]{3}{*}{ São Paulo, Brasil } & \multirow[t]{3}{*}{ Case series } & \multirow[t]{3}{*}{27} & Robotic assisted gastric band placements & \multirow{3}{*}{$\begin{array}{l}6 \text { Gastric band placements, } \\
5 \text { Vertical gastrectomies and } \\
16 \text { Gastric by-pass in Roux-en-Y }\end{array}$} & \multirow[t]{3}{*}{$N R^{1}$} \\
\hline & & & & & Robotic assisted vertical gastrectomies & & \\
\hline & & & & & Robotic asssisted gastric by-pass in Roux-en-Y & & \\
\hline Buchs [16] 2012 & $2006-2010$ & Geneva, Switzerland & Case series & 167 & Robotic-assisted Roux-en-Y gastric bypass & Roux-en-Y gastric bypass & Laparoscopic-Robotic \\
\hline Hagen [7] 2012 & $1997-2010$ & Geneva, Switzerland & CСT & 143 & Robotic-assisted Roux-en-Y gastric bypass & Roux-en-Y gastric bypass & Laparoscopic-Robotic \\
\hline Tieu [17] 2012 & $2002-2010$ & Houston, USA & Case series & 1100 & Robotic-assisted Roux-en-Y gastric bypass & Roux-en-Y gastric bypass & Laparoscopic-Robotic \\
\hline Vilallonga [18] 2012 & 2010-2011 & Barcelona, Spain & Case series & 32 & Robot-Assisted Sleeve Gastrectomy & Sleeve Gastrectomy & Fully Robotic \\
\hline Ayloo [19] 2011 & $2007-2010$ & Chicago, USA & ССТ & 30 & Robot-Assisted Sleeve Gastrectomy & Sleeve Gastrectomy & Fully Robotic \\
\hline Diamantis [20] 2011 & 2008-2009 & Athens, Greece & CCT & 19 & Robotic Sleeve Gastrectomy & Sleeve Gastrectomy & Fully Robotic \\
\hline Edelson [21] 2011 & 2006-2009 & Philadelphia, USA & CCT & 287 & Robotic gastric banding & Gastric banding & Fully Robotic \\
\hline Park [22] 2011 & 2007-2009 & Honolulu, USA & ССТ & 105 & Robotic-assisted Roux-en-Y gastric bypass & Roux-en-Y gastric bypass & NR \\
\hline Scozzari [8] 2011 & 2006-2009 & Torino, Italy & CСT & 110 & Robotic-assisted Roux-en-Y gastric bypass & Roux-en-Y gastric bypass & Fully Robotic \\
\hline Curet [23] 2009 & 2005 & Stanford, USA & ССТ & 21 & Robotic Roux-en-Y gastric bypass & Roux-en-Y gastric bypass & Fully Robotic \\
\hline Deng [24] 2008 & 2006-2007 & Pasadena, USA & Case series & 100 & $\begin{array}{l}\text { Robotic-assisted Laparoscopic Roux-en-Y } \\
\text { gastric bypass }\end{array}$ & Roux-en-Y gastric bypass & Fully Robotic \\
\hline Hubens [25] 2008 & $2004-2006$ & $\begin{array}{l}\text { Antwerpen, } \\
\text { The Netherlands }\end{array}$ & CСT & 45 & Robotic Roux-en-Y gastric bypass & Roux-en-Y gastric bypass & Fully Robotic \\
\hline Sudan [26] 2007 & NR & Omaha, USA & Case series & 47 & $\begin{array}{l}\text { Robotically assisted biliopancreatic } \\
\text { diversion with duodenal switch }\end{array}$ & $\begin{array}{l}\text { Biliopancreatic diversion with } \\
\text { duodenal switch }\end{array}$ & Laparoscopic-Robotic \\
\hline Parini [27] 2006 & 2000-2004 & Aosta, Italy & Case series & 17 & $\begin{array}{l}\text { Laparoscopic gastric bypass performed } \\
\text { with the Da Vinci Intuitive Robotic System }\end{array}$ & Roux-en-Y gastric bypass & Laparoscopic-Robotic \\
\hline Mohr [28] 2006 & $2004-2005$ & Stanford, USA & Case series & 75 & $\begin{array}{l}\text { Totally Robotic Laparoscopic Roux-en-Y } \\
\text { Gastric Bypass }\end{array}$ & Roux-en-Y gastric bypass & Fully Robotic \\
\hline Yu [29] 2006 & $2003-2005$ & Houston, USA & Case series & 100 & $\begin{array}{l}\text { Robotic assistance for laparoscopic } \\
\text { Roux-en-Y gastric bypass }\end{array}$ & Roux-en-Y gastric bypass & Laparoscopic-Robotic \\
\hline Ali [30] 2005 & $2002-2003$ & Sacramento, USA & Case series & 50 & $\begin{array}{l}\text { Robot-assisted laparoscopic Roux-en-Y } \\
\text { gastric bypass }\end{array}$ & Roux-en-Y gastric bypass & Laparoscopic-Robotic \\
\hline Artuso [31] 2005 & $2001-2002$ & New York, USA & Case series & 41 & Laparoscopic gastric bypass performed & Roux-en-Y gastric bypass & Laparoscopic-Robotic \\
\hline
\end{tabular}


Table 1 Characteristics of the included studies: setting and technique (Continued)

\begin{tabular}{|c|c|c|c|c|c|c|c|}
\hline Galvani [32] 2005 & $2000-2004$ & Chicago, USA & Case series & 140 & Robot-assisted surgery & $\begin{array}{l}110 \text { Gastric bypass procedures } \\
30 \text { Lap band }\end{array}$ & Laparoscopic-Robotic \\
\hline Sanchez [33] 2005 & $2004-2005$ & Stanford, USA & RCT & 25 & $\begin{array}{l}\text { Totally robotic laparoscopic Roux-en-Y } \\
\text { gastric bypass }\end{array}$ & Roux-en-Y gastric bypass & Fully Robotic \\
\hline \multirow[t]{3}{*}{ Muhlmann [34] 2003} & \multirow[t]{3}{*}{ NR } & \multirow[t]{3}{*}{ Innsbruck, Austria } & \multirow[t]{3}{*}{ CCT } & \multirow[t]{3}{*}{10} & \multirow{3}{*}{$\begin{array}{l}\text { Robotic-assisted laparoscopic silicone } \\
\text { adjustable gastric banding Robotic } \\
\text { implantable gastric stimulator }\end{array}$} & 4 silicone adjustable gastric banding & \multirow[t]{3}{*}{ Laparoscopic-Robotic } \\
\hline & & & & & & 2 implantable gastric stimulator & \\
\hline & & & & & & $\begin{array}{l}4 \text { silicone adjustable gastric } \\
\text { banding reoperation }\end{array}$ & \\
\hline
\end{tabular}

* Listed in chronological order.

${ }^{1} \mathrm{NR}$ : not reported. 
the full-text of the selected trials were independently screened by two authors (RCand ST) for eligibility. When there was overlapping between multiple articles published by the same authors and no difference in the examined time, only the most recent trial was enclosed to avoid double counting. The Pubmed function "related articles" and Google Scholar database were used to search further articles. We also searched the online database of relevant high-impact journals such as Surgery for Obesity and Related Diseases, Obesity, Obesity review, International Journal of Obesity, Obesity Surgery and Surgical Endoscopy. The references of the included studies were evaluated for other potential trials. The two screening authors evaluated the eligibility of each trial.

\section{Inclusion criteria}

In this systemic review, we considered both comparative and non-comparative studies, irrespectively of their size, publication status and language, which included patients who underwent robotic bariatric surgery . Comparative studies were included if they focused on selected outcomes of interest, irrespectively of the type of surgical approach used for comparative group (laparoscopic or open).

\section{Exclusion criteria}

Studies in which the outcomes of interest were neither reported nor directly or indirectly inferable.

\section{Data extraction}

\section{Primary outcomes}

surgical (conversion to open surgery, anastomotic leakage, re-intervention for complications, mortality), bariatric (postoperative Body Mass Index), and metabolic (type 2 DM remission) outcomes were considered.

\section{Secondary outcomes}

- Surgical ones (major and minor complication rate, pulmonary embolism rate, deep venous thrombosis, 30-days re-admission rate, anastomotic bleeding, gastrojejunostomy anastomotic stricture, post-operative small bowel obstruction, length of hospital stay, operative time).

- metabolic ones (number of patients able to discontinue medical treatment for T2DM at the follow-up and other obesity related morbidities resolution or improvement such as hypertension, sleep apnoea, gastroesophageal reflux and degenerative arthritis).

The included CCT studies were assessed for their methodological quality using the revised and modified grading system of the Scottish Intercollegiate Guidelines
Network (SIGN) [13]; the case series assessment was carried out using the checklist for the quality of case series of the National Institute for Health and Clinical Excellence (NICE) [14]. Two authors (RC and CR) independently extracted data for the listed outcomes and assessed the methodological quality of each study, without masking the authors' names.

\section{Results}

The PRISMA flow chart for systematic review is presented in Figure 1. The initial search produced 132 potentially relevant articles. After the titles and abstracts were screened for relevance, 25 remaining articles were further assessed for eligibility and 3 were excluded; 22 trials whose characteristics are reported in Tables 1 and 2, were included in this systematic review: 1 Randomized Controlled Trial (RCT), 9 Clinical Controlled Trial (CCT) and 12 case series [7,8,15-34]. We excluded the abstract of the largest series trial of robotic-assisted bypass performed in three high-volume centers and presented by Wilson at the American Society for Metabolic \& Bariatric

Table 2 Characteristics of the patients in the included studies

\begin{tabular}{|c|c|c|c|}
\hline Study* & $\begin{array}{l}\text { Mean preoperative } \\
\text { age (years) }\end{array}$ & $\begin{array}{l}\text { Mean weight } \\
\text { [kg] }\end{array}$ & $\begin{array}{l}\text { Mean Body Mass } \\
\text { Index }\left[\mathrm{kg} / \mathrm{m}^{2}\right]\end{array}$ \\
\hline Abdalla [15] & $N R^{1}$ & $N R$ & $N R$ \\
\hline Buchs [16] & 43 & 122.8 & 44 \\
\hline Hagen [7] & 42.6 & $N R$ & 44.5 \\
\hline Tieu [17] & 46.9 & 131.9 & 47.9 \\
\hline Vilallonga [18] & 44.7 & $N R$ & 48.3 \\
\hline Ayloo [19] & 38 & 152 & 57 \\
\hline Diamantis [20] & 39.4 & $N R$ & 48.2 \\
\hline Edelson [21] & 45 & $N R$ & 45.4 \\
\hline Park [22] & 42.2 & $N R$ & 46.77 \\
\hline Scozzari [8] & 42.6 & 127.5 & 46.7 \\
\hline Curet [23] & 46.5 & NR & 45.6 \\
\hline Deng [24] & 41.7 & $N R$ & 48 \\
\hline Hubens [25] & 42 & $N R$ & 44.2 \\
\hline Sudan [26] & 38 & $N R$ & 45 \\
\hline Parini [27] & 42.9 & $N R$ & 50.3 \\
\hline Mohr [28] & 44 & $N R$ & 46.1 \\
\hline Yu [29] & 42 & NR & 50 \\
\hline Ali [30] & 42 & NR & 47 \\
\hline Artuso [31] & 42.5 & 146.2 & 52.8 \\
\hline Galvani [32] & $N R$ & $N R$ & $N R$ \\
\hline Sanchez [33] & 43.3 & $N R$ & 45.5 \\
\hline Muhlmann [34] & $N R$ & NR & 41.5 \\
\hline
\end{tabular}

*Listed in chronological order.

${ }^{1} \mathrm{NR}$ : not reported. 
Table 3 Evaluation of methodological qualities of comparative included studies

\begin{tabular}{|c|c|c|c|c|c|c|c|c|c|c|}
\hline Items/author* & [7] & [19] & [20] & [21] & [22] & [8] & [23] & [25] & [33] & [34] \\
\hline Inclusion criteria & 0 & 1 & 0 & 0 & 1 & 0 & 1 & 1 & 1 & 0 \\
\hline Exclusion criteria & 0 & 0 & 0 & 0 & 0 & 0 & 0 & 0 & 0 & 0 \\
\hline Comparable demographics? & 1 & 1 & 0 & 1 & 1 & 1 & 1 & 1 & 1 & 1 \\
\hline Could the number of participating centres be determined? & 1 & 1 & 1 & 1 & 1 & 1 & 1 & 1 & 1 & 1 \\
\hline Could the number of surgeons who participated be determined? & 1 & 1 & 1 & 1 & 1 & 0 & 0 & 1 & 1 & 1 \\
\hline $\begin{array}{l}\text { Could the reader determine where the authors were on the learning } \\
\text { curve for the reported procedure? }\end{array}$ & 0 & 0 & 1 & 0 & 0 & 1 & 0 & 1 & 1 & 0 \\
\hline Were diagnostic criteria clearly stated for clinical outcomes if required? & 1 & 1 & 1 & 1 & 1 & 1 & 1 & 1 & 1 & 1 \\
\hline Was the surgical technique adequately described? & 1 & 1 & 1 & 0 & 0 & 1 & 0 & 1 & 0 & 1 \\
\hline Did they try to standardize the surgical technique? & 1 & 0 & 1 & 0 & 0 & 1 & 0 & 1 & 0 & 1 \\
\hline Did they try to standardize perioperative care? & 0 & 0 & 0 & 0 & 0 & 0 & 0 & 0 & 0 & 0 \\
\hline Was the age and range given for patients in the Robotic group? & 1 & 0 & 1 & 1 & 1 & 1 & 0 & 1 & 1 & 1 \\
\hline Did the authors address whether there were any missing data? & 1 & 1 & 1 & 1 & 1 & 0 & 1 & 0 & 1 & 0 \\
\hline Was the age and range given for patients in the comparative group? & 1 & 0 & 0 & 1 & 1 & 1 & 0 & 1 & 1 & 1 \\
\hline Were patients in each group treated along similar timelines? & 1 & 1 & 1 & 1 & 1 & 1 & 1 & 1 & 1 & 0 \\
\hline The patients asking to enter the study, did they actually take part to it? & 0 & 0 & 0 & 0 & 0 & 0 & 0 & 0 & 1 & 0 \\
\hline Were drop-out rates stated? & 0 & 0 & 0 & 0 & 0 & 0 & 0 & 0 & 1 & 0 \\
\hline Were outcomes clearly defined? & 1 & 1 & 1 & 1 & 1 & 1 & 1 & 1 & 1 & 1 \\
\hline Were there blind assessors? & 0 & 0 & 0 & 0 & 0 & 0 & 0 & 0 & 0 & 0 \\
\hline Were there standardized assessment tools? & 1 & 0 & 0 & 0 & 0 & 0 & 0 & 0 & 1 & 0 \\
\hline Was the analysis by intention to treat? & 0 & 0 & 0 & 0 & 0 & 0 & 0 & 0 & 1 & 0 \\
\hline Score & 12 & 9 & 10 & 9 & 10 & 10 & 7 & 12 & 15 & 9 \\
\hline
\end{tabular}

Total score, $21 ;<8$, poor quality; $8-14$, fair quality; $\geq 15$, good quality.

* Named by reference number and listed in chronological order.

Surgery Annual Meeting in San Diego (2012) due to the limited data available in the abstract. [35]. The methodological quality according to the modified grading system of the Scottish Intercollegiate Guidelines Network resulted of fair quality for each of the 10 comparative studies included (mean score 10.3 points) (Table 3). The methodological quality assessment of the case series included proved a fair quality of the selected items evaluated with the NICE checklist (mean score 4.9 points) ( Table 4). The pooled data included 2.781 (patients range per study:

Table 4 Evaluation of methodological qualities of observational included studies

\begin{tabular}{|c|c|c|c|c|c|c|c|c|c|c|c|c|}
\hline Items/author* & [15] & [16] & [17] & [18] & [24] & [26] & [27] & {$[28]$} & [29] & [30] & [31] & {$[32]$} \\
\hline Case series collected in more than one centre, i.e. multi-centre study & 0 & 0 & 1 & 0 & 0 & 0 & 0 & 0 & 0 & 0 & 0 & 0 \\
\hline Is the hypothesis/aim/objective of the study clearly described? & 1 & 1 & 1 & 1 & 1 & 1 & 1 & 1 & 1 & 1 & 1 & 1 \\
\hline Are the inclusion andexclusion criteria (case definition) clearly reported? & 1 & 1 & 1 & 1 & 1 & 1 & 1 & 0 & 1 & 0 & 0 & 0 \\
\hline Is there a clear definition of the outcomes reported? & 1 & 1 & 1 & 1 & 1 & 1 & 1 & 1 & 1 & 1 & 1 & 0 \\
\hline Were data collected prospectively? & 0 & 1 & 1 & 0 & 0 & 0 & 0 & 0 & 1 & 1 & 0 & 0 \\
\hline $\begin{array}{l}\text { Is there an explicit statement that patients were recruited } \\
\text { consecutively? }\end{array}$ & 0 & 0 & 1 & 1 & 1 & 0 & 1 & 1 & 1 & 0 & 0 & 0 \\
\hline Are the main findings of the study clearly described? & 0 & 1 & 1 & 1 & 1 & 1 & 1 & 1 & 1 & 1 & 1 & 0 \\
\hline $\begin{array}{l}\text { Are outcomes stratified? (e.g., by disease stage, abnormal test } \\
\text { results, patient characteristics) }\end{array}$ & 0 & 0 & 0 & 1 & 1 & 0 & 1 & 1 & 1 & 1 & 1 & 0 \\
\hline Total Score & 3 & 5 & 7 & 6 & 6 & 4 & 6 & 5 & 7 & 5 & 4 & 1 \\
\hline
\end{tabular}

Yes $=1 \mathrm{No}$ (not reported, not available) $=0$.

Total score, $8 ; \leq 3$, poor quality; $4-6$, fair quality; $\geq 7$, good quality.

* Named by reference number and listed in chronological order. 
10-1.100 patients) who were planned to receive Robotic bariatric surgical treatment: 2.225 RRYGB, 86 Robotic Sleeve gastrectomy (RSG), 421 silicone adjustable gastric band, 47 bilio-pancreatic diversion with a duodenal switch and 2 implantable gastric stimulator. We excluded from our analysis implantable gastric stimulator (2 patients) and silicone adjustable gastric band reoperation ( 2 patients). The definition of the robotic approach given in the included studies was very heterogeneous: fully robotic, robotic, robotic-assisted and robotassisted laparoscopy. The dissection and the resection were also heterogeneous and sequentially combining different approaches: laparoscopic/robotic and only robotic.

\section{Primary outcomes}

- Surgical Outcomes: The data listed in Table 5 suggest that robotic bariatric surgery is feasible, regardless of the type of treatment $(99.9 \%$ in RYGB $-100 \%$ in

RSG, 100\% in silicone adjustable gastric band, $93.62 \%$ in biliary pancreatic diversion with duodenal switch).

The analysis revealed a very low anastomotic leak rate ( $0.29 \%$ of gastrojejunostomy and $0.05 \%$ of jejunojejunostomy in RYGB, 0\% in SG, $0.25 \%$ in silicone adjustable gastric band, $8.51 \%$ in biliary pancreatic diversion with duodenal switch).

The 30-day post-operative reoperation rate was very low (1.14\% in RYGB and $1.16 \%$ in SG) (Table 5). No study reported any case of 30-day postoperative mortality (Table 5).

- Bariatric outcome (postoperative Body Mass Index): only few trials reported the reduced mean BMI after 3 months from the RYGB $[7,8,18,24,27,28]$ and SG [20] (Table 5).

- Metabolic outcomes: none of the studies reported data on the metabolic outcome.

\section{Secondary outcomes}

- Surgical Outcomes: major complication rates were $4,26 \%$ in RYGB and 1,2\% in SG; minor complication rates were $1 \%$ in RYGB and 0\% in SG; Pulmonary embolism rates were $0,71 \%$ in RYGB 0\% in RSG; deep venous thrombosis rates were $0,37 \%$ in RYGB and 0\% in SG; 30-day re-admission rates were 4,84\% in RYGB and 0\% in SG (Table 6). 15 cases of

Table 5 Primary outcomes

\begin{tabular}{|c|c|c|c|c|}
\hline Study & Intraoperative conversions & 30-day reoperations & 30-day postoperative mortality & $\begin{array}{l}\text { Mean body mass index } \\
3 \text { months after surgery }\end{array}$ \\
\hline Abdalla [15] & 0 & 1 & 0 & $N R^{1}$ \\
\hline Buchs [16] & 2 & 2 & 0 & NR \\
\hline Hagen [7] & 2 & 1 & 0 & 44.5 \\
\hline Tieu [17] & 0 & NR & 0 & 39.8 \\
\hline Vilallonga [18] & 0 & 0 & 0 & NR \\
\hline Ayloo [19] & 0 & 1 & 0 & NR \\
\hline Diamantis [20] & 0 & 0 & 0 & reduced of $31.3 \%$ \\
\hline Edelson* [21] & 0 & 11 & 0 & NR \\
\hline Park [22] & 1 & 1 & 0 & NR \\
\hline Scozzari [8] & 0 & 2 & 0 & reduced of $33.6 \%$ \\
\hline Curet [23] & NR & NR & 0 & NR \\
\hline Deng [24] & NR & 0 & 0 & $17.5 \%$ \\
\hline Hubens [25] & 9 & 2 & 0 & NR \\
\hline Sudan [26] & 3 & NR & 0 & NR \\
\hline Parini [27] & 0 & 0 & 0 & 39.07 \\
\hline Mohr [28] & 4 & NR & 0 & reduced of $48 \%$ \\
\hline Yu [29] & 0 & 2 & 0 & NR \\
\hline Ali [30] & NR & NR & NR & NR \\
\hline Artuso [31] & NR & NR & NR & NR \\
\hline Galvani [32] & NR & NR & NR & NR \\
\hline Sanchez [33] & 1 & NR & NR & NR \\
\hline Muhlman [34] & NR & NR & 0 & NR \\
\hline
\end{tabular}

* Listed in chronological order.

${ }^{1} \mathrm{NR}$ : not reported. 
Table 6 postoperative complications and 30 day readmission in the included studies

\begin{tabular}{|c|c|c|c|c|c|}
\hline Study* & $\begin{array}{l}\text { 30-day major } \\
\text { complications }\end{array}$ & $\begin{array}{l}\text { 30-day minor } \\
\text { complications }\end{array}$ & $\begin{array}{l}\text { Pulmonary } \\
\text { embolism }\end{array}$ & $\begin{array}{l}\text { Deep venous } \\
\text { thrombosis }\end{array}$ & $\begin{array}{l}\text { Readmissions in the first } \\
30 \text { postoperative days }\end{array}$ \\
\hline Abdalla [15] & 1 & 5 & 0 & 0 & $\mathrm{NR}^{1}$ \\
\hline Buchs [16] & 24 (not classified) & & 7 & 2 & 2 \\
\hline Hagen [7] & 23 (not classified) & & NR & NR & NR \\
\hline Tieu [17] & 45 & 102 & 2 & 3 & 67 \\
\hline Vilallonga [18] & 1 case & NR & NR & NR & NR \\
\hline Ayloo [19] & NR & & NR & NR & 0 \\
\hline Diamantis [20] & 0 (not classified) & & 0 & 0 & 0 \\
\hline Edelson [21] & NR & & NR & NR & NR \\
\hline Park [22] & 10 (not classified) & & 0 & 0 & 0 \\
\hline Scozzari [8] & 4 & 14 & 1 & NR & $N R$ \\
\hline Curet [23] & 3 (not classified) & & NR & NR & $N R$ \\
\hline Deng [24] & 4 & 7 & NR & NR & 3 \\
\hline Hubens [25] & NR & NR & NR & NR & $N R$ \\
\hline Sudan [26] & NR & NR & NR & NR & NR \\
\hline Parini [27] & 0 & 0 & 0 & 0 & 0 \\
\hline Mohr [28] & 6 & 7 & NR & NR & NR \\
\hline Yu [29] & NR & NR & 1 & NR & $N R$ \\
\hline Ali [30] & NR & NR & NR & NR & NR \\
\hline Artuso [31] & NR & NR & NR & NR & NR \\
\hline Galvani [32] & NR & NR & NR & NR & NR \\
\hline Sanchez [33] & NR & NR & NR & NR & NR \\
\hline Muhlmann [34] & NR & NR & NR & NR & $N R$ \\
\hline
\end{tabular}

* Listed in chronological order.

${ }^{1}$ NR: not reported.

anastomotic bleeding were reported over a total of 1.873 RYGB while none were reported in SG (Tables 7, 8). Gastrojejunostomy anastomotic stricture rate was $1,23 \%$ in RYGB. Post-operative small bowel obstruction rates were $1,17 \%$ in Roux-en-Y gastric bypass and $0 \%$ in sleeve gastrectomy (Tables 7, 8). The mean hospital stay ranged between 2.72 and 7.4 days in RYGB and between 2.6 and 4 days in SG (Table 9). The mean operative time ranged between 130.8 and 295 min. in RYGB and between 95 and 135 min. in SG (Table 9).

- Metabolic outcomes: none of the studies reported this outcome.

\section{Discussion}

The present study revealed slightly different outcomes and complication rates between the traditional laparoscopic approach and the robotic one. Data from a RCT collected after laparoscopic gastric bypass showed that 1-year mortality is about $0.9 \%$, Major perioperative complications (hemorrhage, obstruction, internal herniation, or renal insufficiency) occur in $6.3 \%$ of patients and late ( $>30$ days postoperatively) major complications, more often stenosis or strictures, in $26.1 \%$ of them [36]. The results of this review demonstrated that the robotic approach is safe and feasible in all types of bariatric surgical procedures. The overall post-operative complication rate was very low; in particular the anastomotic leak rate (gastro-jejunostomy and jejuno-jejunostomy in RYGB) and the gastric staple line leak rate were very low and no deaths were reported. The analysis of these selected trials on the robotic bariatric surgery did not show any significant results about the bariatric and the metabolic outcomes. Our results were in line with the ones presented in 2012 by Wilson et al. at the Annual Meeting of the American Society for Metabolic \& Bariatric Surgery in San Diego [35]. In this trial the authors enrolled 1,695 patients undergoing robotic-assisted RYGB surgery; the post-operative complications were 17 bowel obstructions, 5 wound infections and 18 cases of bleeding. The hospital readmissions rate was $4.8 \%$ and re-intervention rate was $2.7 \%$. Leak and anastomotic stricture rates were very low: $0.3 \%$ and $0.2 \%$ respectively. No death was reported. "This report of the largest series of robotic-assisted bypasses from 
Table 7 Surgical complications after gastric bypass

\begin{tabular}{|c|c|c|c|c|c|}
\hline \multirow[t]{2}{*}{ Study* } & \multicolumn{2}{|c|}{ Post-operative anastomotic leak } & \multirow{2}{*}{$\begin{array}{l}\text { Anastomotic stricture } \\
\text { Gastro-jejunostomy }\end{array}$} & \multirow{2}{*}{$\begin{array}{l}\text { Anastomotic } \\
\text { bleeding }\end{array}$} & \multirow{2}{*}{$\begin{array}{l}\text { Post-operative } \\
\text { bowel obstruction }\end{array}$} \\
\hline & g-j & $\mathrm{j}-\mathrm{j}$ & & & \\
\hline Abdalla [15] & 0 & 0 & 0 & 0 & 0 \\
\hline Buchs [16] & 0 & 0 & 3 & $N R^{3}$ & 1 \\
\hline Hagen [7] & 0 & 0 & 0 & 3 & NR \\
\hline Tieu [17] & 1 & 1 & 7 & 9 & 19 \\
\hline Park [22] & 2 & 0 & 2 & 0 & 0 \\
\hline Scozzari [8] & 2 & 0 & 3 & 0 & 1 \\
\hline Curet [23] & 0 & 0 & 0 & 0 & 0 \\
\hline Deng [24] & 1 & 0 & 4 & 3 & 0 \\
\hline Hubens [25] & 0 & 0 & 2 & 0 & 1 \\
\hline Parini [27] & 0 & 0 & 0 & 0 & 0 \\
\hline Mohr [28] & 0 & 0 & 2 & 0 & 0 \\
\hline Yu [29] & 0 & 0 & 2 & 0 & 0 \\
\hline Ali [30] & NR & NR & NR & NR & NR \\
\hline Artuso [31] & 1 & 0 & 0 & 0 & 0 \\
\hline Galvani [32] & NR & NR & NR & $N R$ & NR \\
\hline Sanchez [33] & NR & NR & NR & $N R$ & NR \\
\hline
\end{tabular}

* Listed in chronological order.

${ }^{3} \mathrm{NR}$ : not reported.

three high-volume centers reveals very low complication rates in the first 30 days. It reveals zero 30-day mortality, an exceptionally low leak rate, and provides strong evidence that Robot-Assisted RYGB (RARYGB) has extremely safe and reproducible outcomes" [35]. Robotic surgery allowed the reduction of the postoperative complications, especially the anastomotic dehiscence. The low anastomotic leak rate after robotic bypass can be partially explained by the improved accuracy and precision of intracorporeal suturing compared to the traditional laparoscopic approach. $5 \mathrm{~cm}$ proximal to the anastomosis, an antireflux longitudinal valve is fashioned with suture stitches $1 \mathrm{~cm}$ apart from each other. In USA the RARYGB represent the first line choice of bariatric surgery, but because of its "complexity", this operation has always been challenged by alternative surgical procedures [37].

Safety of gastric bypass was demonstrated and its effectiveness in the long term weight loss maintenance as well, nevertheless it associates with a long learning curve and it is not free from complications $[38,39]$. Kim et al. concluded that the use of the robot is ideal in performing RYGB [40]. This technique associates with shorter learning curve especially in performing delicate and precise manoeuvres such as fine dissections and suturing. Indeed it is widely recognized that robotic bariatric surgery, in particular RRYGB, has a steeper learning curve than laparoscopic approach and 20 cases may be enough to pass the basic learning phase [41]. Moreover this technique, unlike laparoscopic surgery, can be used in high-risk obese patients with difficult anatomy without compromising the surgical performance and outcomes [40]. The best results derived from the RSG that showed even fewer postoperative complications and no mortality, but the use of the robot in performing sleeve gastrectomy is still controversial, and not largely spread among bariatric surgeons yet. Recently few case series on this technique were published $[19,20]$. Robotic approach was demonstrated associating with shorter learning curve compared to the traditional laparoscopic techniques [37]. A poster presented

Table 8 Surgical complications after sleeve gastrectomy and duodenal switch

\begin{tabular}{llllll}
\hline Surgical treatment & Study & Suture leak & Suture stricture & Suture bleeding & Bowel obstruction/internal hernia \\
\hline Sleeve gastrectomy & Vilallonga [18] & 0 & 0 & 0 & 0 \\
& Ayloo [19] & 0 & 1 & 0 & 0 \\
& Diamantis [20] & 0 & 0 & 0 & 0 \\
Duodenal switch & Sudan [26] & 4 & 0 & 0 & 0 \\
\hline
\end{tabular}




\begin{tabular}{|c|c|c|}
\hline Study* & $\begin{array}{l}\text { Mean operative } \\
\text { time (min.) }\end{array}$ & $\begin{array}{l}\text { Length of hospital stay } \\
\text { Mean } \pm \text { Standard deviation (days) }\end{array}$ \\
\hline Abdalla [15] & $N R^{1}$ & NR \\
\hline Buchs [16] & 295.2 & $7.2 \pm 2.5$ \\
\hline Hagen [7] & 293 & $7.4 \pm 2.6$ \\
\hline Tieu [17] & 155 & NR \\
\hline Vilallonga [18] & 130.2 & NR \\
\hline Ayloo [19] & 135 & 2.6 \\
\hline Diamantis [20] & 95.5 & 4 \\
\hline Edelson [21] & 91.5 & 1.3 \\
\hline Park [22] & 169 & $3.41 \pm 7.03$ \\
\hline Scozzari [8] & 247.5 & 7.8 \\
\hline Curet [23] & 181.7 & 3 \\
\hline Deng [24] & 186.3 & 1.5 \\
\hline Hubens [25] & 242.2 & 4.7 \\
\hline Sudan [26] & 514 & NR \\
\hline Parini [27] & 201 & 9 \\
\hline Mohr [28] & 140 & 2.9 \\
\hline Yu [29] & 254 & NR \\
\hline Ali [30] & NR & NR \\
\hline Artuso [31] & 289 & 4.6 \\
\hline Galvani [32] & NR & NR \\
\hline Sanchez [33] & 130.8 & 2.72 \\
\hline Muhlman [34] & 137 & 3 \\
\hline
\end{tabular}

*Listed in chronological order.

${ }^{1} \mathrm{NR}$ : not reported.

in by Miller et al. at the annual meeting of the Society of American Gastrointestinal and Endoscopic Surgeons (SAGES) compared 277 laparoscopic sleeve Gastrectomy (LSG) to 40 RSG. The mean operative time was significantly shorted (91 minutes) for LSG compared to the RSG (113 minutes) ( $\mathrm{p}-0.002)$ No differences were revealed in overall mean hospital stay (2.4 days in the LSG group and 2.5 in the RSG group) ( $\mathrm{p}=0.86)$. The overall mean 90 -day complication rate requiring readmission was significantly lower in patients who had undergone RSG (12.3\% in the LSG group and 5\% in RSG group) $(\mathrm{p}=<.001)$ [42].

\section{Conclusion}

Robotic assistance is used in a small percentage of bariatric procedures in the US. The major limitation of our analysis is the lack of studies and their low quality, small sample size, heterogeneity of enrolled patients and the lack of data from metabolic and bariatric outcomes. Despite the use of the robot, the majority of these cases are completed with stapled anastomosis. The assumption that robotic surgery is superior in complex cases is not supported from actual evidence. According to our experience the major strength of the robotic surgery is strongly facilitating some of the surgical steps (gastro-jejunostomy and jejunojejunostomy anastomosis in the robotic Roux-en-Y gastric bypass or the vertical gastric resection in the robotic sleeve gastrectomy). According to our experience the major disadvantage of the robotic bariatric surgery "still remains the high operational and acquisition cost of the system" [37].

\section{Additional file}

Additional file 1: PRISMA Checklist.doc.

\section{Competing interest}

The Authors all report no conflicts of interest. Furthermore for the writing of this paper the Authors didn't benefit of any source of funding.

\section{Authors' contributions}

RC designed and concepted the manuscript, performed the interpretation of data, drafted and revised critically the manuscript. CB designed, concepted and revised critically the manuscript. AS analyzed the data and revised the manuscript. SG designed, drafted and revised the paper. PC took part to the interpretation of data and revised the manuscript. CR was involved in the acquisition of data, in their analysis and in drafting the manuscript. $\mathrm{CL}$ contributed to the acquisition of data and she took part in drafting the manuscript. ST performed the interpretation of data, drafted and revised critically the manuscript. JD took part to the acquisition of data, in their analysis and in drafting the manuscript. AC was involved in the interpretation of data and revised the manuscript. GN designed, concepted and revised critically the manuscript. AR designed, concepted and revised critically the manuscript. AP concepted and revised critically the manuscript. All authors read and approved the final manuscript and they agree to be accountable for all aspects of the work in ensuring that questions related to the accuracy or integrity of any part of the work are appropriately investigated and resolved.

\section{Acknowledgments}

The authors are the only ones responsible for the content and writing of the paper.

\section{Author details}

'Department of Digestive and Liver Surgery Unit, St Maria Hospital, Terni, Italy. ${ }^{2}$ Department of General and Oncologic Surgery, University of Perugia, Perugia, Italy. ${ }^{3}$ Department of Surgical Sciences, "Sapienza" University of Rome, Rome, Italy. ${ }^{4}$ Department of General Surgery, Misericordia Hospital, Grosseto, Italy.

Received: 11 June 2013 Accepted: 1 November 2013 Published: 7 November 2013

\section{References}

1. Gastrointestinal surgery for severe obesity: National Institutes of Health consensus development conference statement. Am J Clin Nutr 1992, 55(2):615S-619S.

2. Gregg EW, Cheng YJ, Narayan KM, Thompson TJ, Williamson DF: The relative contributions of different levels of overweight and obesity to the increased prevalence of diabetes in the United States: 1976-2004. Prev Med 2007, 45:348-52.

3. Davis MM, Slish K, Chao C, Cabana MD: National trends in bariatric surgery. 1996-2002. Arch Surg 2006, 141(1):71-74.

4. Adams TD, Pendleton RC, Strong MB, et al: Health outcomes of gastric bypass patients compared to nonsurgical, nonintervened severely obese. Obesity 2010, 18(1):121-130.

5. Schirmer B: Laparoscopic gastric bypass. In Surgical pitfalls. Edited by Evans SRT. Philadelphia: Saunders Elsevier; 2009:197-222.

6. Markar SR, Karthikesalingam AP, Venkat-Ramen V, Kinross J, Ziprin P: Robotic vs laparoscopic Roux-en-Y gastric bypass in morbidly obese patients: systematic review and pooled analysis. Int J Med Robot 2011, 7(4):393-400. 
7. Hagen ME, Pugin F, Chassot $G$, et al: Reducing cost of surgery by avoiding complications: the model of robotic Roux-en-Y gastric bypass. Obes Surg 2012, 22(1):52-61.

8. Scozzari G, Rebecchi F, Millo P, Rocchietto S, Allieta R, Morino M: Robot-assisted gastrojejunal anastomosis does not improve the results of the laparoscopic Roux-en-Y gastric bypass. Surg Endosc 2011, 25(2):597-603.

9. Fourman MM, Saber AA: Robotic bariatric surgery: a systematic review. Surg Obes Relat Dis 2012, 8(4):483-488.

10. Gill RS, Al-Adra DP, Birch D, et al: Robotic-assisted bariatric surgery: a systematic review. Int J Med Robot 2011. doi: 10.1002/rcs.400.

11. Markar SR, Penna M, Hashemi M: Robotic bariatric surgery: bypass, band and sleeve. Where are we now? And what is the future?

Minerva Gastroenterol Dietol 2012, 58(3):181-190.

12. Moher D, Liberati A, Tetzlaff J, Altman DG: Preferred reporting items for systematic reviews and meta-analyses: the PRISMA statement. PLoS Med 2009, 6(7):e1000097.

13. Scottish Intercollegiate Guidelines Network (SIGN) guidelines, methodology checklist 3. [http://www.sign.ac.uk/methodology/checklists.html]

14. National Institute for Health and Clinical Excellence. NICE clinical guidelines, Appendix 4 Quality of case series form. [http://www.nice.org.uk/ nicemedia/ pdf/Appendix_04_qualityofcase_series_form_preop.pdf]

15. Abdalla RZ, Garcia RB, Luca CR, Costa Rl, Cozer CO: Brazilian experience in obesity surgery robot-assisted. Arq Bras Cir Dig 2012, 25(1):33-35.

16. Buchs NC, Bucher $P$, Pugin $F$, et al: Value of performing routine postoperative liquid contrast swallow studies following robot-assisted Roux-en-Y gastric bypass. Swiss Med Wkly 2012, 142:W13556. doi:10.4414/smw.2012.13556.

17. Tieu K, Allison N, Snyder B, Wilson T, Toder M, Wilson E: Robotic-assisted Roux-en-Y gastric bypass: update from 2 high-volume centers. Surg Obes Relat Dis 2013, 9(2):284-288.

18. Vilallonga R, Fort JM, Gonzales O, et al: The initial learning curve for Robot-Assisted Sleeve Gastrectomy: a surgeon's experience while introducing the robotic technology in a bariatric surgery department. Minimally Invasive Surgery 2012. doi:10.1155/2012/347131.

19. Ayloo S, Buchs NC, Addeo P, Bianco FM, Giulianotti PC: Robot-assisted sleeve gastrectomy for super-morbidly obese patients. J LaparoendosC Adv Surg Tech A 2011, 21(4):295-299.

20. Diamantis T, Alexandrou A, Nikiteas N, Giannopoulos A, Papalambros E: Initial experience with robotic sleeve gastrectomy for morbid obesity. Obes Surg 2011, 21(8):1172-1179.

21. Edelson PK, Dumon KR, Sonnad SS, Shafi BM, Williams NN: Robotic vs. conventional laparoscopic gastric banding: a comparison of 407 cases. Surg Endosc 2011, 25(5):1402-1408.

22. Park CW, Lam EC, Walsh TM, et al: Robotic-assisted Roux-en-Y gastric bypass performed in a community hospital setting: the future of bariatric surgery? Surg Endosc 2011, 25(10):3312-3321.

23. Curet MJ, Solomon H, Liu G, Morton JM: Comparison of hospital charges between robotic, laparoscopic stapled, and laparoscopic handsewn Roux-en-Y gastric bypass. J Robot Surg 2009, 3(3):199.

24. Deng JY, Lourié DJ: 100 robotic-assisted laparoscopic gastric bypasses at a community hospital. Am Surg 2008, 74(10):1022-1025.

25. Hubens G, Balliu L, Ruppert M, Gypen B, Van Tu T, Vaneerdeweg W: Roux-en-Y gastric bypass procedure performed with the da Vinci robot system: is it worth it? Surg Endosc 2008, 22(7):1690-1696.

26. Sudan R, Puri $V$, Sudan D: Robotically assisted biliary pancreatic diversion with a duodenal switch: a new technique. Surg Endosc 2007, 21(5):729-733.

27. Parini U, Fabozzi M, Contul RB, et al: Laparoscopic gastric bypass performed with the Da Vinci Intuitive Robotic System: preliminary experience. Surg Endosc 2006, 20(12):1851-1857.

28. Mohr CJ, Nadzam GS, Alami RS, et al: Totally robotic laparoscopic Roux-en-Y gastric bypass: results from 75 patients. Obes Surg 2006, 16:690-696.

29. Yu SC, Clapp BL, Lee MJ, Albrecht WC, Scarborough TK, Wilson EB: Robotic assistance provides excellent outcomes during the learning curve for laparoscopic Roux-en-Y gastric bypass: results from 100 robotic-assisted gastric bypasses. Am J Surg 2006, 192(6):746-749.

30. Ali MR, Bhaskerrao B, Wolfe BM: Robot-assisted laparoscopic Roux-en-Y gastric bypass. Surg Endosc 2005, 19:468-472.

31. Artuso D, Wayne M, Grossi R: Use of robotics during laparoscopic gastric bypass for morbid obesity. JSLS 2005, 9(3):266-268.
32. Galvani $C$, Horgan S: Robots in general surgery: present and future. Cir Esp 2005, 78(3):138-147.

33. Sanchez BR, Mohr CJ, Morton JM, et al: Comparison of totally robotic laparoscopic Roux-en-Y gastric bypass and traditional laparoscopic Roux-en-Y gastric bypass. Surg Obes Relat Dis 2005, 1:549-554.

34. Mühlmann G, Klaus A, Kirchmayr W, et al: DaVinci robotic-assisted laparoscopic bariatric surgery: is it justified in a routine setting? Obes Surg 2003, 13(6):848-854.

35. Wilson EB, Toder M, Snyder BE, Wilson TD, Kim K: Favorable early complications of robotic assisted gastric bypass from three high volume centers: 1,695 consecutive cases. San Diego, CA: Presented at the 29 th American Society for Metabolic \& Bariatric Surgery Annual Meeting; 2012

36. Nguyen NT, Slone JA, Nguyen XM, Hartman JS, Hoyt DB: A prospective randomized trial of laparoscopic gastric bypass versus laparoscopic adjustable gastric banding for the treatment of morbid obesity: Outcomes, quality of life, and costs. Ann Surg 2009, 250(4):631-41.

37. Garza U, Echeverria A, Galvani C: Robotic-Assisted Bariatric Surgery. In Advanced Bariatric and Metabolic Surgery. Edited by Huang CK. Shanghai: InTech; 2012:297-316.

38. Podnos YD, Jimenez JC, Wilson SE, Stevens CM, Nguyen NT: Complications after laparoscopic gastric bypass: a review of 3464 cases. Arch Surg 2003, 138(9):957-961.

39. Trastulli S, Desiderio J, Guarino S, et al: Laparoscopic sleeve gastrectomy compared with other bariatric surgical procedures: a systematic review of randomized trials. Surg Obes Relat Dis 2013, 9(5):816-29.

40. Kim KC, Buffington C: Totally robotic gastric bypass: approach and technique. J Robot Surg 2011, 5(1):47-50.

41. Buchs NC, Pugin F, Bucher $P$, et al: Learning curve for robot-assisted Roux-en- $Y$ gastric bypass. Surg Endosc 2012, 26(4):1116-21.

42. Miller N, Wilson E, Snyder B, et al: Comparison of Laparoscopic vs. Robotic Assisted Longitudinal Sleeve Gastrectomy. San Diego, CA: Presented at the Society of American Gastrointestinal and Endoscopic Surgeons (SAGES) annual meeting; 2012.

doi:10.1186/1471-2482-13-53

Cite this article as: Cirocchi et al:: Current status of robotic bariatric surgery: a systematic review. BMC Surgery 2013 13:53.

\section{Submit your next manuscript to BioMed Central and take full advantage of:}

- Convenient online submission

- Thorough peer review

- No space constraints or color figure charges

- Immediate publication on acceptance

- Inclusion in PubMed, CAS, Scopus and Google Scholar

- Research which is freely available for redistribution 